\title{
Key Factors on the Spotlight as Predictors of Dietary Adherence Among Patients Living with Type 2 Diabetes
}

\author{
Nekesa Carolyne Musee ${ }^{1,}$, , David Omondi Okeyo1, Wycliffe Odiwuor² \\ ${ }^{1}$ Department of Nutrition and Health, Maseno University, Kisumu, Kenya \\ ${ }^{2}$ Department of Education Psychology, Maseno University, Kisumu, Kenya
}

Email address:

museecaro@yahoo.com (N. C. Musee), jandigwa@yahoo.co.uk (D. O. Okeyo), odwicky@gmail.com (W. Odiwuor)

${ }^{*}$ Corresponding author

\section{To cite this article:}

Nekesa Carolyne Musee, David Omondi Okeyo, Wycliffe Odiwuor. Key Factors on the Spotlight as Predictors of Dietary Adherence Among Patients Living with Type 2 Diabetes. European Journal of Preventive Medicine. Vol. 4, No. 5, 2016, pp. 106-112. doi: 10.11648/j.ejpm.20160405.11

Received: July 12, 2016; Accepted: July 30, 2016; Published: September 5, 2016

\begin{abstract}
There is a rise in prevalence of Type 2 diabetes in Kenya, and an increase in related complications, which lead to disability and death. Diet modification oriented for this group of patients includes recommendations to control blood sugar, lipid levels and pressure which are vital in lowering risk and complications development in the management of Type 2 diabetes. Studies indicate that adherence to diet therapy is weak in the midst of diet recommendations and patients' education. There seems to be limited literature in developing countries as to the most critical factors in the prediction mix of adherence. This article attempts to display the competitiveness between socio-demographic and patient education related factors in the context of adherence. Across sectional analysis of a sample of 240 eligible diabetics was used and their dietary behaviour evaluated using a pre-tested dietary habit assessment survey tool with socio-demographic and patient-focus education factors. Linear regression preceded by principle axis factoring to categories adherences was executed. The results indicated that diet characterized by control of lipid levels was influenced by diet accessible within distance from home $(\beta=0.211, t=2.053$, $\rho=0.041)$, while diet to control blood sugar and pressure was influenced by diet accessible from the workplace $(\beta=0.193$, $\mathrm{t}=2.027, \rho=0.044)$, occupation status $(\beta=0.162, \mathrm{t}=2.051, \rho=0.042)$, age $(\beta=0.178, \mathrm{t}=2.238, \rho=0.026)$, marital status $(\beta=0.208$, $\mathrm{t}=2.731, \rho=0.007)$ and diet found in the locality or surrounding environment $(\beta=0.277, t=3.034, \rho=0.003)$. In conclusion, adherence enhancement seems to draw reference to education sessions focused on challenges faced by the unmarried, age specifics, occupation, setting specifics.
\end{abstract}

Keywords: Type 2 Diabetes, Diet Adherence, Socio-Economic Factors, Patient Factors

\section{Introduction}

The prevalence of Type 2diabetes in Kenya has shown an increasing trend from $3.3 \%$ in 2010 to a projection of $4.5 \%$ in $2025[26,29]$ and a growth in the disease burden $[12,21$, 24]. In the course of time, untreated diabetes results in blindness, kidney failure and lower limb amputation, and also leads to the onset of cardiovascular disease, the leading cause of death in diabetes patient's [5, 15, 32]. Studies show that weight and diet management, improve metabolic outcome and reduce the risk of complications development, in Type 2 diabetes [7, 9, 10] [16, 21, 27, 34] This implies a relation in the management of Type 2 diabetes using diet to reduce complications and death from untreated diabetes. Yet, other studies have shown, that the extent to which patients follow the recommended diet regime given by a health care provider, also defined as adherence to diet [33], is below optimal in most cases, ranging from $22 \%$ to $70 \%[2,6,30]$. The American Diabetes Association (ADA) and the Kenya National Clinical Guidelines in the Management of Diabetes Mellitus (KNCGMD), mention as part of the dietary management of Type 2 diabetes, considering other factors such as individual needs and preferences, traditional eating and cultural practices, palatability and affordability of the food, dietary counseling and deliberate efforts made to enhance adherence $[1,4,29]$. Several studies have attributed non-adherence to factors such as diet monotony, taste 
preferences, cost, poverty, eating out, long visit intervals, poor health provider-patient relation ship, poor self discipline, lack of information or not understanding the information well [2, 3, 23].

In Africa, non-adherence to diet in the management of conditions has been associated with several socio-economic factors. These include gender, urbanization, cost of food, irregular follow up by primary care giver, poor patient-health giver relations, lack of information or not well understood information, level of education, tendency to eat out and lack of self-discipline [2, 20, 23]. In Kenya, non-adherence to treatment has been associated with among other things, poverty, since $46 \%$ of Kenyans live on less than a dollar per day and may not afford the recommended diet [29] taste of the food, diet monotony and sharing of food rations with other family members [11]. Studies in Kenya have shown non-adherence even when patients acknowledged that they had received dietary advice and could as well afford the recommended dietor were given food rations [3, 28], implying that there could exist underlying reasons for nonadherence in such cases.

A recent study done in Kenya, revealed that patients managing Type 2 diabetes would adhere more to some diet recommendations than others, unveiling a pattern focused on adherence aimed at managing different complications [28]. It means that even though patients undergo the Medical Nutrition Therapy (MNT), aimed at an all-round adherence to all diet recommendations, there are still other factors affecting adherence to diet, and more so to some particular diets. The indication here is that even though several socioeconomic reasons have been cited for non-adherence in different parts of Kenya and of the world, the specifics of these non-adherence to different diet recommendations are yet to be identified. Studies on non-adherence have been generalised, and unless the real issues affecting adherence to different diet recommendations are identified, they can not be addressed to effectively manage the development of complications. In order to improve dietary management of Type 2 diabetes, it is important to establish the socioeconomic factors that influence adherence to each diet recommendation. This study therefore sought to identify the socio-economic factors affecting diet adherence in the management of Type 2 diabetesamong eligible patients in Jaramogi Oginga Odinga Teaching and Referral Hospital.

\section{Materials and Methods}

This study adopted a cross sectional study design. Data was collected within a period of three months and analyzed once. This study design was chosen because it does not allow for any manipulation of factors and provides population characteristics as they occur at one point in time. The study was carried out at in Kenya, in Jaramogi Oginga Odinga Teaching and Referral Hospital, which is the major referral hospital in Nyanza, Western and North Rift, serving over 12 districts in Nyanza alone and with a catchment population of over 5 million people in the three provinces [31]. The population of this study was made up of all Type 2 Diabetes clinic attendees aged 35 years and above. This age group is more independent in terms of decision-making, which may include what and how they eat [40]. A sampling frame of 480 patients was arrived at based on the average number of individual patients who visit the clinic every day and the length of time it would take before they made their second visit

The sample, which consisted of 238 diabetic patients, was determined by the formula proposed by Yamane in 1967. The formula is as shown below; $\mathrm{n}=\mathrm{N} / 1+\mathrm{N}(\mathrm{e})^{2}$

Where $\mathrm{n}$ is sample size

$\mathrm{N}$ is population size and is the level of precision: $\mathrm{n}=\mathrm{N} / 1+\mathrm{N}(\mathrm{e})^{2}=480 / 1+480(0.05)^{2}=218$ patients

The sample size was increased by $10 \%$ to account for contingencies such as non-response and recording error.

Therefore, $10 / 100$ of $218=21.8=22$, giving a total sample size of $218+22=240$ individuals [38]

Within the context of measurement, dependent variable was mainly diet adherence pattern generated through preliminary factor loadings. This was defined as the manner in which patients follow health provider recommended diets. It was derived by assessing how different diet recommendation statements accounted for a diet adherence factor.

Independent underlying variables included key factorsuspects such as age, occupation, area of residence, length of time they had been managing Type 2 diabetes, sex, marital status, employment status, if the recommended diet was affordable, accessible and or culturally accepted.

\section{Results}

\subsection{Dietary Adherence Pattern}

To derive an adherence pattern, which would give direction on why patients adhere, factor extraction based on standard Eigen values set at $1[14,36]$ and varimax rotated, revealed that it was possible to derive five common factors that had a unit variance of more than one, and were possible diet adherence factors among the study population. It means therefore that it was possible to extract five principle components that account for more variance, than that accounted for by each of the 12 recommended diet attributes. All the five factors of diet adherence, accounted for $37.62 \%$ of the variance in dietary adherence.

The first diet adherence factor (AF1), accounted for $11.8 \%$ of the total variance in dietary adherence, and was a reflection of two recommended diet statements, use of cooking oil and reduced intake of fats, depicting lipid control diet. The second diet adherence factor (AF2), was able to account for $10.96 \%$ of the total variance in dietary adherence. It was in turn a reflection of five recommended diet statements; reduced intake of foods with high glycemic index, reduced intake of margarine and or butter, reduced use of simple sugar in beverages, reduced intake of sugar 
flavoured drinks and snacks, and reduced intake of salted snacks depicting sugar, lipid and blood pressure control diet. The third diet adherence factor, (AF3), accounted for $5.79 \%$ of the total variance in dietary adherence and was a reflection of two recommended diet statements indicators. These were carbohydrate intake from whole grain and reduced intake of table salt depicting sugar and pressure control. The fourth and fifth diet adherence factors (AF4 and AF5) were able to account for $4.99 \%$ and $4.06 \%$ respectively of the total variance in dietary adherence. Adherence factors AF4 and AF5 were a reflection of recommended diet statements include fruits in all meals and include vegetables in all meals, respectively depicting promotion of healthy diet.

Table 1. Extracted diet adherence pattern among type 2 diabetics' regular clinic attendees.

\begin{tabular}{|c|c|c|c|c|c|}
\hline \multirow{2}{*}{ Recommended diet statements } & \multicolumn{5}{|c|}{ Diet adherence factors after varimax rotation } \\
\hline & AF1 & AF2 & AF3 & AF4 & AF5 \\
\hline Da1-Carbohydrate intake is from whole grain & & & .556 & & \\
\hline Da2-Reduce intake of foods with high glycemic index & & .590 & & & \\
\hline Da3-Use of cooking oils & .918 & & & & \\
\hline Da4-Reduce intake of margarine and or butter & & .415 & & & \\
\hline Da5-Reduce intake of fats & .703 & & & & \\
\hline Da6-includes vegetables in all meals & & & & & .419 \\
\hline Da8-Reduce use of simple sugar in beverages & & .478 & & & \\
\hline Da9-Reduce intake of simple sugar flavoured drinks & & .499 & & & \\
\hline Da10-Reduce intake of table salt & & & .549 & & \\
\hline Da11-Reduce intake of salted snacks & & .509 & & & \\
\hline Da12-Adhere to diet plan & & & & & \\
\hline Variance Explained & $11.8 \%$ & $10.96 \%$ & $5.79 \%$ & $4.99 \%$ & $4.06 \%$ \\
\hline
\end{tabular}

Key: AF1- Adherence Factor One, AF2- Adherence Factor Two, AF3- Adherence Factor Three, AF4- Adherence Factor Four, AF5- Adherence Factor Five

\subsection{Key Factors Linked to Dietary Adherence}

This article is built on the results of an earlier article purely oriented on diet adherence nature [28]. Five categories of adherence form the basis for indentifying critical factors.

\subsubsection{Lipid, Sugar and Pressure Control}

This included adherence factors 1, 2, and 3. Adherence factor one focused on controlling blood lipid levels as proxy to cardiovascular diseases, diet accessible by distance was the only significant factor $(\beta=0.211, \mathrm{t}=2.053, \rho=0.041)$. Accessing the required foods within their area of residence was the only contributing factor to adherence factor one was more influential than diet being accessible from the work place.

Diet adherence factor two, which focused on controlling lipid, blood sugar and hypertension, had diet accessible from workplace $(\beta=0.193, \mathrm{t}=2.027, \rho=0.044)$ and occupation status, that is what they do to earn a living $(\beta=0.162, \mathrm{t}=2.051$, $\rho=0.042$ ) as significant predictors. Diet being accessible from their work place, and occupation status, that is being employed or self-employed or unemployed, facilitated the efforts to reduce foods with a high glycemic index, reduce of sugar in beverages, reduce intake of sugar flavored drinks, reduce intake of margarine and or butter, and salted snacks. In this case though, occupation status, was less influential. Finally, for adherence factor three, whose focus was to reduce sugar and pressure levels age $(\beta=0.178, \mathrm{t}=2.238$, $\rho=0.026)$, marital status $(\beta=0.208, t=2.731, \rho=0.007)$ and diet available in the environment $(\beta=0.277, \mathrm{t}=3.034, \rho=0.003)$ were the most key predictors. An increase in age and food being available in their locality increased adherence to intake of whole grain carbohydrate and a reduction of salt intake. On the other hand, the need to lower the risk of complications development increases as one moves from being single to married to being a widow/widower or divorced.

Table 2. Predictors of dietary adherence in relation to lipid, sugar and blood pressure control.

\begin{tabular}{|c|c|c|c|c|c|}
\hline \multirow{2}{*}{ Patient and socio-economic factors } & \multicolumn{2}{|c|}{ Unstandardized Coefficients } & \multirow{2}{*}{$\begin{array}{l}\text { Standardized Coefficients } \\
\text { Beta }\end{array}$} & \multirow{2}{*}{$\mathbf{t}$} & \multirow{2}{*}{ Sig. } \\
\hline & B & Std. Error & & & \\
\hline Lipid control diet. & .150 & .920 & & .163 & .870 \\
\hline Age & -.004 & .008 & -.043 & -.541 & .589 \\
\hline Sex & .270 & .180 & .124 & 1.50 & .135 \\
\hline Education level & .120 & .103 & .095 & 1.161 & .247 \\
\hline Marital status & -.152 & .098 & -.118 & -1.55 & .124 \\
\hline Occupation status & -.015 & .116 & -.010 & -.126 & .900 \\
\hline Are you on Diabetic medication & .265 & .551 & .035 & .481 & .631 \\
\hline Advice given on diet & -.113 & .145 & -.057 & -.777 & .438 \\
\hline Diet affordable & -.045 & .064 & -.057 & -.711 & .478 \\
\hline Diet accepted culturally & .037 & .255 & .011 & .146 & .884 \\
\hline Diet accessible by distance & .246 & .120 & .211 & 2.053 & .041 \\
\hline Diet accessible - work place & -.112 & .110 & -.098 & -1.02 & .309 \\
\hline
\end{tabular}




\begin{tabular}{|c|c|c|c|c|c|}
\hline \multirow{2}{*}{ Patient and socio-economic factors } & \multicolumn{2}{|c|}{ Unstandardized Coefficients } & \multirow{2}{*}{$\begin{array}{l}\text { Standardized Coefficients } \\
\text { Beta }\end{array}$} & \multirow{2}{*}{$\mathrm{t}$} & \multirow{2}{*}{ Sig. } \\
\hline & B & Std. Error & & & \\
\hline Diet available in environment & -.037 & .119 & -.028 & -.307 & .759 \\
\hline Diabetes in the family & .022 & .152 & .010 & .146 & .884 \\
\hline Sugar, lipid and blood pressure control diet & -1.12 & 1.10 & & -1.02 & .312 \\
\hline Age & .011 & .010 & .089 & 1.122 & .263 \\
\hline Sex & .048 & .215 & .018 & .222 & .825 \\
\hline Education level & -.025 & .123 & -.016 & -.202 & .840 \\
\hline Marital status of respondent & -.150 & .118 & -.096 & -1.274 & .204 \\
\hline Occupation status & .285 & .139 & .162 & 2.051 & .042 \\
\hline Period of treatment & -.001 & .001 & -.089 & -1.245 & .215 \\
\hline On Diabetic medication & -.152 & .658 & -.016 & -.231 & .818 \\
\hline Advice given on diet & .023 & .173 & .010 & .133 & .894 \\
\hline Diet affordable & .112 & .076 & .117 & 1.470 & .143 \\
\hline Diet accepted culturally & .265 & .304 & .065 & .870 & .385 \\
\hline Diet accessible by distance & .123 & .143 & .088 & .860 & .391 \\
\hline Diet accessible - work place & .267 & .132 & .193 & 2.027 & .044 \\
\hline Diet available -environment & -.001 & .143 & -.001 & -.007 & .994 \\
\hline Diabetes in the family & .159 & .182 & .061 & .872 & .384 \\
\hline Sugar and blood pressure control & -.256 & 1.260 & & -.203 & .839 \\
\hline Age & .025 & .011 & .178 & 2.238 & .026 \\
\hline Sex & .166 & .247 & .055 & .673 & .502 \\
\hline Education level & -.033 & .141 & -.019 & -.232 & .817 \\
\hline Marital status of respondent & .368 & .135 & .208 & 2.731 & .007 \\
\hline Occupation status & -.026 & .159 & -.013 & -.161 & .873 \\
\hline Period of treatment & -.001 & .001 & -.036 & -.496 & .621 \\
\hline On Diabetic medication & .115 & .755 & .011 & .152 & .879 \\
\hline Advice given on diet & -.054 & .199 & -.020 & -.272 & .786 \\
\hline Diet affordable & .036 & .088 & .033 & .416 & .678 \\
\hline Diet accepted culturally & -.425 & .349 & -.091 & -1.217 & .225 \\
\hline Diet accessible by distance & .160 & .164 & .100 & .978 & .329 \\
\hline Diet accessible - work place & .156 & .151 & .099 & 1.030 & .304 \\
\hline Diet available - environment & .496 & .164 & .277 & 3.034 & .003 \\
\hline Diabetes in the family & .167 & .209 & .057 & .801 & .424 \\
\hline
\end{tabular}

\subsubsection{Sugar, Pressure Control and Healthy Diet Promotion}

Adherence factor four, whose focus was on boosting the body's immune had no significant predictors while adherence factor five, also focusing on healthy diet promotion had one significant predictor, marital status of the respondent $(\beta=0.209, \mathrm{t}=2.725$, $\rho=0.007$ ). The need to promote health by including vegetables and fruits in all meals, increases as one moves from being single to married status to being a widow/widower or divorced.

Table 3. Socio-economic and patient factors for adherence factor five.

\begin{tabular}{|c|c|c|c|c|c|}
\hline \multirow{2}{*}{ Socio-economic and patient factors } & \multicolumn{2}{|c|}{ Unstandardized Coefficients } & \multirow{2}{*}{$\begin{array}{l}\text { Standardized Coefficients } \\
\text { Beta }\end{array}$} & \multirow[t]{2}{*}{$\mathbf{t}$} & \multirow[t]{2}{*}{ Sig. } \\
\hline & B & Std. Error & & & \\
\hline Sugar and pressure control. & .737 & 1.315 & & .560 & .576 \\
\hline Age & .015 & .012 & .107 & 1.331 & .185 \\
\hline Sex & .063 & .257 & .020 & .245 & .807 \\
\hline Education level & .052 & .148 & .029 & .354 & .723 \\
\hline Marital status of respondent & -.190 & .141 & -.104 & -1.353 & .178 \\
\hline Occupation status & -.204 & .166 & -.098 & -1.225 & .222 \\
\hline On Diabetic medication & -.202 & .788 & -.019 & -.257 & .798 \\
\hline Advice given on diet & -.102 & .208 & -.036 & -.492 & .623 \\
\hline Diet affordable & -.085 & .091 & -.075 & -.931 & .353 \\
\hline Diet accepted culturally & .171 & .365 & .036 & .468 & .640 \\
\hline Diet accessible by distance & .021 & .171 & .013 & .122 & .903 \\
\hline Diet accessible at work place & -.087 & .158 & -.053 & -.549 & .584 \\
\hline Diet available within residential environment & -.141 & .171 & -.076 & -.828 & .409 \\
\hline Diabetes in the family & -.322 & .218 & -.106 & -1.48 & .141 \\
\hline Age & -.005 & .013 & -.032 & -.399 & .691 \\
\hline Sex & .054 & .284 & .016 & .191 & .849 \\
\hline Education level & -.080 & .163 & -.040 & -.493 & .623 \\
\hline Marital status of respondent & .423 & .155 & .209 & 2.725 & .007 \\
\hline Occupation status & .216 & .183 & .094 & 1.182 & .239 \\
\hline Period of treatment & -.001 & .002 & -.033 & -.458 & .647 \\
\hline
\end{tabular}




\begin{tabular}{|c|c|c|c|c|c|}
\hline \multirow{2}{*}{ Socio-economic and patient factors } & \multicolumn{2}{|c|}{ Unstandardized Coefficients } & \multirow{2}{*}{$\begin{array}{l}\text { Standardized Coefficients } \\
\text { Beta }\end{array}$} & \multirow[t]{2}{*}{$\mathrm{t}$} & \multirow[t]{2}{*}{ Sig. } \\
\hline & B & Std. Error & & & \\
\hline On Diabetic medication & .627 & .868 & .052 & .723 & .471 \\
\hline Advice given on diet & -.365 & .229 & -.117 & -1.597 & .112 \\
\hline Diet affordable & .111 & .101 & .089 & 1.106 & .270 \\
\hline Diet accepted culturally & -.219 & .402 & -.041 & -.545 & .586 \\
\hline Diet accessible by distance & -.302 & .189 & -.165 & -1.602 & .111 \\
\hline Diet accessible at work place & .272 & .174 & .151 & 1.568 & .119 \\
\hline Diet available within residential environment & .009 & .188 & .004 & .045 & .964 \\
\hline Diabetes in the family & .054 & .240 & .016 & .224 & .823 \\
\hline
\end{tabular}

\section{Discussion}

The study looked at the role of socio-demographic and patients related possible factors for adherence to diet in the context of management of Type 2 diabetes. Of specific importance was age, marital status, sex, diabetes in the family, education levels, period with diabetes and culture. Patient factors were measured by affordability of the recommended diet and occupation, while other factors assessed availability of the recommended diet within the distance, area of residence and workplace. Age, marital status, diet found in the locality or surrounding environment, diet accessible by distance, diet accessible from the workplace, occupation status emerged as key spotlight factors in adherence model. These study results, did not fully agree with other studies that have concluded that socio-economic factors are weak in predicting adherence [13, $39,41]$. Although in this study sex did not have an influence on adherence, other studies have indicated that women are twice more likely to be depressed [22] leading to a dissatisfaction with care and subsequently, poor adherence to diabetes self-care [8]. In another study in which socioeconomic factors were assessed against adherence, the results showed that age, gender, education levels and income did not influence adherence [37]. This study highlights a scenerio which refelcts the opposite where age appeared to influence diet adherence. The length of time one has been managing diabetes, did not appear to influence adherence, but has shown conflicting results in other studies. While the World Health Organisation suggests that the long period in managing chronic diseases such as diabetes will evetually lead to nonadherence [33], another study found that patients who have been managing diabetes for a long period are more llikely to adhere to diet and medication [35]. This current study, however, did not show any signifcant asscoiation of length of time in managing Type 2 diabetes as a potential risk factor.

Adherence factor one (lipid control diet), whose focus was to manage lipid levels as s proxy of control cardio-vascular diseases (CVD), by increasing use of oils and reducing fat intake somehow increasedby diet accessibility (distance).In other words, the nearer the point where they could access cooking oils or foods made with cooking oils, the more they were able to adhere to adherence factor one. Patients presenting to the clinic with an inability to control blood lipid levels have to be probed to find out how far they have to move to access low fat diets, and possible solutions for the right kind of substitutes be given. For adherence factor two (Lipid, sugar and pressure control), whose focus combined control of blood lipids, glucose and possible progrssion to hypertention, an increase in diet being available at the work place and occupation status were able to increase with adherence.In other words, the fact that patients could access the modified diet from their workplace, whether they were employed or self employed increased adherence to reduing intake of foods with a high glycemic index, reducing use of sugar in beverages, reducing intake of sugar flavoured drinks and snacks, reducing intake of margarine and or butter and salted snacks. The implication therefore is that if these foods are not available at the workplace, whether employed or self employed, then they would not be able to adhere. An increase in age, marital status and having the required foods grown in the locality led to an increase in diet adherence factor three (sugar and pressure control diet). This diet adherence factor was focused on lowering the risk of complications such as hypertentison, by reducing salt intake and increasing whole grain carbohydrates intake. The fact that age and marital status led to an increase in adherence of this factor, could be explained by the fact that as people grow older, they are also more likely to marry, thus their effect could be the same. To support this finding, one study revealed that marital status and or having a family member with knowledge about diabetes care influenced its management $[17,25]$ and that if a family member had knowledge then they were supportive to diabetes management leading to increased adherence to treatment regimes. Marital status also led to an increase in adherence factor five (healthy diet promotion), whose focus was on maintaining healthy eating through vegetable consumption.

Therefore, these results provide a basis upon which health care providers may need to focus on to ensure that adherence levels are met. When drawing a diet plan to control the onset of CVD, it would be important to know how far they have to move from their homes in order to get the required foods. In the same way, to control blood glucose and prevent the development of complications it would be important to provide alternatives for ensuring that they are able to access the modified diet from their work place for the employed and self employed, such as packing their own lunch. Considering that for those who have to work in an urban setting the temptation of fast food joints and supermarkets offering ready to eat could lead to non-adherence. Since the required foods being grown in the locality led to an increase in adherence, it is important to find out where they access their food from to understand if they are more likely to adhere or not and provide adequate solutions. Marital status which seemed to influence adherence factor three and five cannot be ignored. It therfore 
implies that special attention be given to single people or those who stay alone, to ensure that they are supported more to adhere to these two adherence factors. Diet modification in the management of Type 2 Diabetes is aimed at controlling blood sugar, lipid levels and pressure. This study highlights the socio economic factors that affect efforts to manage the three areas, and provides information that can isolate and handle each area depending on clinical diagnosis.

The study revealed that several socio-economic factors had an influence on the different adherence domains. Adherence to control cardiovascular diseases increased as the required foods became accessible by distance, highlighting the need to focus on patients in marginalized areas. On the other hand, adherence to control blood glucose and development of complications increased with an increase in diet accessibility from their workplace and their employment status, meaning that employers should make efforts to ensure that their employees with Type 2 diabetes are able to access the required foods while at work. To lower the risk of progression to complications, adherence increases with age, marital status and required food grown in the locality. This implies giving closer attention during counseling to younger, unmarried and patients from urban settings who may not be able to grow the food. Finally, adherence to promote and maintain healthy diet increased with marital status, again requiring more focus in dealing with this fact among the youth.

\section{Conclusion and Recommendation}

In conclusion, this study has identified key factors on the spotlight of adherence prediction in the context of diabetes management. Top on the list are, diet accessibility within distance from home, diet accessibility from the workplace, occupation status, age, marital status and diet found in the locality or surrounding environment. As Kenya receives global recognition for developing plans to target noncommunicable diseases [19], this study recommends that the Kenya National Clinical Guidelines in the management of Type 2 Diabetes Mellitus (KNCGMD) include a chapter on how counseling sessions should address social factors that affect diet adherence. They should also advocate for deliberate efforts by all the involved stakeholders to manage diabetes. These include but are not limited to; the Government of Kenya, to facilitate an infrastructure network and policies that enhance availability and accessibility to required foods even in marginalized parts of the country, the Federation of Kenya Employers (FKE) to provide guidelines on the role of the employer in the management of employees with Type 2 diabetes, among other stakeholders.

\section{References}

[1] ADA. (2013). Standards of Medical Care in Diabetes Management. Diabetes Care, 511-566.

[2] Adewale, B. G., Langalibalele, H. M., Malete, H. N., Govendar, I., \& Ogunbanjo, A. G. (2013). Non-Adherence to
Diet and Excercise Regime Amongst Patients with Type 2 Diabtes Mellitus Attending Extension II Clinic in Botswana. Care Farm Medicine, 1-6.

[3] Ayieko, W. (2011). Prevalence of Lifestlye Risk Factors Among Diabetic Patients at Kenyatta National Hospital. Nairobi: Nairobi University.

[4] Bantle, J. P., Rossett, J. W., Albright, A. L., Apovian, C. M., Clark, N. G., Franz, M. J., Wheeler, M. L. (2008). Nutrition Recommendations and Interventions for Diabetes: A Position Statement of the American Diabetes Association. Diabetes Care, 61-78.

[5] Boyle, J. P., Theodore, T. J., Gregg, E. W., Barker, L. E., \& Williamson, D. F. (2010). Projection of the year 2050 Burden of Diabetes in the US Adult Poppulation: Dynamic Modeling of Incidence, Mortaltiy and Prediabetes Prevalence. Population Health Metrics, 8(29).

[6] Broadbent, E., Donkin, L., \& Stroh, J. C. (2011). Illness and Treatment with Adherence to Medications, Diet and Excercise in Diabetic Patients. Diabetes Care, 34, 338-340.

[7] Chorzempa, A. (2006). Type 2 Diabetes Mellitus and It's effects on Vascular Disease. Journal of Cardiovascular Medicine, 21(6), 485-492.

[8] Ciechanowski, P. S., Katon, W. S., Russo, S. E., \& Hirsh, I. B. (2003). The Relationship of Depression Symptoms to Symptoms Reporting, Self-Care and Glucose Control in Diabetes. General Hospital Psychiatry, 246-252.

[9] Copell, K. J., Kataoka, M., Williams, S. M., Chrisholm, A. W., Vorgers, M. S., \& Mann, J. L. (2010, May 19). Nutrition Intervention in Patients with Type 2 Diabetes Who are Hyperglycaemic Despite Optimised Drug Treatment-Lifestyle Over and Above Drugs (LOADD) Study: Randomised Control Trial. Otago, Dunedin, New Zealand.

[10] Cornier, M.-A., Dabelea, D., Hernandez, T. L., Lindstrom, R. C., Steig, A. J., \& Stob, N. R. (2008). The Metabolic Syndrome. Endocrine Review, 29(7), 777-822.

[11] Dibari, F., Bahwere, P., Gall, L., Guerro, S., Mwaniki, D., \& Seal, A. (2012). A Qualitative investigation of Adherence to Nutritional Therapy in Malnourished AIDS patients in Kenya. Public Health Nutrition, 316-323.

[12] Dropkin, B. M. (2010). An approaching epidemic: Exploring Diabetes Awareness and Care in Mombasa, Kenya. Unpublished paper, School for international training, Kenya.

[13] Freita, R. W., Araujo, M. F., Marinho, N. B., Damasceno, M. M., Caetan, J. A., \& Galvao, M. T. (2011). Factors Related To Nursing Diagnosis, Ineffective Self Health Management Among Diabetics . Acta Paul Enferm, 365-372.

[14] Gorsuch, R. L. (1983). Factor Analysis (2nd ed.). Hillsdale: Lawrence Erbaum Associates.

[15] Gregg, E. W., Gu, Q., Williams, D., de Rekeneire, N., Cheng, Y. J., Geiss, L., \& Engelgau, M. (2007). Prevalence of Lower Extremity Associated with Normal Glucose Levels, Impaired Fasting Glucose and Diabetes among US Adults aged 40 or Older. Diabetes Resolution Clinic, 458-488.

[16] Gutschall, M. D., Miller, C. K., Mitchell, D. C., \& Lawrence, F. (2009). A Randomised Behavioural Trial Targetting Glycaemic Index Improves Dietary Weight and Metabolic Outcomes in Patients with Type 2 Diabetes. Public Health Nutrition, 1-9. 
[17] Gutschall, M., Onega, L. L., \& Wright, W. K. (2011). Patients' Percpectives about Dietary Maintenance in Type 2 Diabetes. Tropical Clinical Nutrtion, 180-189.

[18] Hodge, A. M., English, D. R., O'dea, K., \& Giles, G. G. (2004). Glycemic Index and Diet Fibre and the Risk of Type 2 diabetes. Diabetes Care, 2701-2706.

[19] IFPRI. (2016). Global Nutrition Report 2016: From Promise to Impact. Ending Malnutrition by 2030. Washington DC: International Food Policy Research Institute.

[20] Kalyango, J., Owino, E., \& Nambuya, A. (2008). NonAdherence to Diabetes Treatment at Mualgo Hospitals in Uganda: Prevalence and Associated Factors. African Health Services, 67-73.

[21] Kayima, J. K. (2002). The Changing Spectrum of Type 2 Diabetes Mellitus. East African Medical Journal, 397-399.

[22] Kessler, R. C. (2003). Epidemiology of Women Depression. Journal of Affected Disorders, 5-13.

[23] Khan, A. R., Al-Abdul, L. Z., Al Aithan, M. A., BuKhamseen, M. A., Al Ibrahim, I., \& Khan, S. A. (2012). Factors Contributing to a Non Compliance Among Diabetics Attending Primary Health Centres in the Al Hasa District of Saudi Arabia. Journal of Family and Community Medicine, 26-32.

[24] Mario, A., \& Sridavi, A. (2008). Diabetes in Sub Saharan Africa: Kenya, Mali, Mozambique, Nigeria, South Africa and Zambia. International Journal of Diabetes in Developing Countries, 101-108.

[25] Mayberry, L. S., \& Osborn, C. Y. (2012). Family Support, Medical Adherence and Glycemic Control Among Adults with Type 2 Diabetes. Diabetes Care, 1239-1245.

[26] McFerran, L. (2008). Obstacles to Diabetes Care in Kenya. Medical Journal of Therapeutics Africa, 2(2), 127-129.

[27] Miller, C. K., Edwards, L., Kissling, G., \& Sanville, L. (2002). Evaluation of a Theory- Based Nutrtion Intervention for Older Adults with Diabetes Mellitus. Journal of America Medical Association, 1069-1074, 1079-1081.

[28] Musee, C. N., Okeyo, D. O., \& Odiwuor, W. H. (2016). Dietary Adherence Pattern in The Context of Type 2 Diabetic Management within Clinical Setting, Kenya. International Journal of Diabetes Research, 26-34.

[29] National Diabetes Control Programme. (2010, July). Kenya National Diabetes Strategy 2010-2015. Nairobi, Nairobi, Kenya: Ministry of Public Health and Sanitation.
[30] Peyrot, M., Rubin, R. R., Lauritzen, T., Snoek, F. J., Mathews, D. R., \& Skovland, S. E. (2005). Psychological Barriers to Improve Diabetes Management: Results of the CrossNational Diabetes Attitudes, Wishes and Needs (DAWN) Study. Diabetic Medication, 1379-1385.

[31] PPOA. (2010). New Nyanza Provincial General Hospital Procurement Review. Nairobi: Public Procurement Oversight Authority.

[32] Roglic, G., \& Unwin, N. (2010). Mortality Attributable to Diabetes: Estimates for the Year 2010. Diabetes Resolution Clinic Practice, 87(1), 15-19.

[33] Sabate, E. (2003). Adherence to Long Term Therapies: Evidence for Action. Geneva: World Health Organisation.

[34] Steyn, N. P., Lambert, E. V., \& Tabana, H. (2009). Nutrition Interventions for the Prevention of Type 2 Diabetes. Conference on 'Multidiscplinary Approaches to Nutritional Problems' Symposium on "Diabetes and Health" (pp. 55-70). Cape Town: Nutrition Society.

[35] Silva, L., Ribeiro, P., \& Cardoso, H. (2006). Diabetes Mellitus Treatment Adherence; The Relevance of Demographic and Clinical Characterisitics. Science Medicine, 33-41.

[36] Tabachnick, B. G., \& Fidell, L. S. (1996). Using Multivariate Statisitics (3rd ed.). New York: Harper Collins.

[37] Turcatto, H., Faria, G., Fernanda, F., Rodriguez, L., Zanetti, M. L., Flavio, M., Damasceno, C. (2013). Factors Associated with Adherence to Treatment of Patients with Diabetes Mellitus. Acta Paul Enferm, 231-237.

[38] Yamane, T. (1967). Statistics: An Introductory Analysis. New York: Harper and Row.

[39] Yang, Y., Thumula, V., Pace, P. F., Banahan, B. F., Wilken, N. E., \& Lobb, W. B. (2009). Predictors of Medicine NonAdherence Among Patients with Diabetes in Medicare Part D Program; A Retrospective Cohort Study. Clinical Therapy, 2178-2188.

[40] Zepeda, E., Leigh, F., Ndirangu, L., Omollo, J., \& Wainaina, S. (2013). Discussion Paper: Kenya's Youth Employment Challenge. New York: UNDP.

[41] Zhu, V. S., Tu, W., Marrero, D. J., Rosenman, M. B., \& Overhage, J. M. (2011). Race and Medication Adherence and Glycemic Control; Findings from an Operational Health Information Exchange. AMIA Annual Syposium, 1649-57. 